\title{
Polymer-layered silicate nanocomposites in the design of antimicrobial materials
}

\author{
Rinat Nigmatullin $\cdot$ Fengge Gao $\cdot$ Viktoria Konovalova
}

\begin{abstract}
A robust processing of polymers into antimicrobial materials is introduced using polymer/clay nanotechnology. Antimicrobial activity of commercially available organoclays modified with cationic surfactants has been screened in tests against gram-negative Escherichia coli and gram-positive Staphylococcus aureus bacteria. Despite the leaching biocidal surfactants, cell interactions with organoclay surface have been identified to be responsible for antimicrobial activity of organoclays. Distribution of clay platelets within polymer matrix by melt extrusion process resulted in polymer/clay nanocomposites active against both gram-positive and gram-negative bacteria by contact. The study discloses a much overlooked function of organoclays modified with cationic surfactants for nanocomposite application, i.e., the ability of organoclays to render polymer nanocomposites biocidal.
\end{abstract}

\section{Introduction}

In the past two decades, the idea of using layered clay minerals for polymer nanocomposite applications has flourished resulting in the development of advanced materials with

\footnotetext{
R. Nigmatullin $(\bowtie) \cdot$ F. Gao

School of Science and Technology, Nottingham Trent University, Clifton Lane, Nottingham NG11 8NS, UK

e-mail: rinat.nigmatullin@ntu.ac.uk

F. Gao

e-mail: fengge.gao@ntu.ac.uk

V. Konovalova

Department of Chemistry, National University of Kiev-Mohyla

Academy, 2 Skovoroda Street, Kiev 04070, Ukraine

e-mail: vita@ukma.kiev.ua
}

improved mechanical, thermal, electrical, barrier, and optical properties $[1,2]$. This progress was enabled by the utilization of specially designed organophilic clays as nanofillers in polymer composites [3, 4]. Conceptually, clay modification intends the intercalation of organophilic substances into the interlayer space of the layered silicates to weaken the interlayer interactions, increase the interlayer spacing, and improve clay-polymer compatibility. This allows macromolecules to penetrate into the interlayer space during processing, leading to the separation of the individual layers and uniform dispersion of the separated clay layers in a polymer matrix. The versatile roles of organoclays in the formation of polymer/clay nanocomposites and their potential in improving a wide range of properties of polymers demonstrate multifunctionality of clay minerals in polymer composites.

Most of the organoclays for nanocomposite application are produced through ion exchange of the metal cations within the original clay with organophilic cations such as quaternary ammonium salts. The important feature of these organic modifiers is the presence of long hydrophobic chain(s) in the organic cations $[5,6]$. Such substances are also highly effective against a broad spectrum of microorganisms and widely used as antimicrobial agents [7].

The use of mineral clays as biocide carriers has been reported previously with the predominant application of inorganic biocides, such as $\mathrm{Ag}, \mathrm{Cu}, \mathrm{Zn}$, etc. [8-10] Biocidal metals can be incorporated into the clay structure as charge compensating ions via ion exchange. Alternatively, nanoparticles of neutral metals can be formed inside the clay gallery by the reduction of metals salts loaded into a clay [9]. However, there are very few reports in the open literatures concerning the antimicrobial activity of clays loaded with organic biocides. The available information on this so far includes the use of organoclays containing 
benzyl- or alkylammonium salts as antimicrobial additives to topical cosmetic formulations [11] or in delivery systems [12]; bacteria removal by clays modified with cetylpyridinium in water treatment applications [13]; and the use of cationic organic molecules, chlorhexidine acetate [14], and chitosan $[15,16]$, which are well-known disinfectants, to intercalate into layered silicates to produce antimicrobial organoclays.

These sporadic researches into biocidal organoclays have not yet involved their applications in polymer nanocomposites until recent research of polyurethane (PU) nanocomposites for biomedical applications $[15,16]$. It was shown that the introduction of an organoclay into PU matrix significantly suppressed biofilm formation on the material surface exposed to the bacterial suspension [15]. At the same time, these studies raised a concern of the applicability of such composites as implantable biomaterials since nanocomposites were cytotoxic $[15,16]$. Nevertheless such an approach can open a new route toward much-sought materials with self-sterilising surfaces.

In this paper, the feasibility of using clay/polymer nanotechnology has been further explored with a view to developing polymer composites with antimicrobial properties. Clay/polymer nanocomposites have been prepared by the melt processing with the use of commercially available organoclays. Nanocomposites with platelets of alkylammonium-modified clays dispersed in a polymer matrix showed activity against both gram-positive and gram-negative bacteria. This work reveals a new function of organoclays in polymer/clay nanocomposite application and opens up a new approach in the preparation of advanced polymer materials with antimicrobial activity in addition to enhanced physical and engineering properties.

\section{Experimental}

\section{Materials}

The organoclays were supplied by the Southern Clay Products and were montmorillonites modified with the following quaternary ammonium salts: dimethyl, benzyl, hydrogenated tallow quaternary ammonium chloride (Closite 10A, surfactant content $125 \mathrm{meq} / 100 \mathrm{~g}$ clay); methyl, hydrogenated tallow, bis-2-hydroxyethyl quaternary ammonium chloride (Closite 30B, surfactant content $90 \mathrm{meq} / 100 \mathrm{~g}$ clay); dimethyl, dihydrogenated tallow quaternary ammonium chloride (Closite 15A, surfactant content $125 \mathrm{meq} / 100 \mathrm{~g}$ clay; Closite 20A, surfactant content $95 \mathrm{meq} / 100 \mathrm{~g}$ clay); methyl, dihydrogenated tallow ammonium bisulfate (Cloisite 93A, surfactant content 90 meq/100 g clay). The nylon- 6 studied was Ultramid $^{\circledR}$ B3 purchased from BASF.
Nanocomposite preparation

Nylon-6/clay nanocomposites were prepared by melt extrusion at $240{ }^{\circ} \mathrm{C}$ using a $16 \mathrm{~mm}$ twin screw extruder (length/diameter $=24 / 1$ ) with a screw speed of $400 \mathrm{rpm}$ and feeding rate of $20 \%$. Two series of nanocomposites were produced using pre-dried and mixed formulations of polyamide/clay: one series with content of each organoclay 5 wt. $\%$ and a second series of nylon-6/Cloisite $15 \mathrm{~A}$ containing 1, 2, 5 or $10 \mathrm{wt} . \%$ of organoclay. The extruded strands were pelletized and dried in a vacuum oven at $80{ }^{\circ} \mathrm{C}$ for $10 \mathrm{~h}$ before processing into square samples $\left(25 \times 25 \times 1 \mathrm{~mm}^{3}\right)$ by injection moulding for the subsequent XRD characterization and microbiological testing. The temperature applied in the injection moulding was $270{ }^{\circ} \mathrm{C}$.

Clay and nanocomposite characterization

The XRD characterization of the organoclays and nanocomposites were carried out using a Philips XPert Pro XRD (PANalytical, USA) with $\mathrm{CuK} \alpha$ radiation at $40 \mathrm{kV}$ and $30 \mathrm{~mA}$.

Migration of surfactants from the clay and nanocomposites into an aqueous medium was studied as follows. Two pieces of polymer plates with dimension $20 \times 20 \times 1 \mathrm{~mm}^{3}$ were immersed into $20 \mathrm{~mL}$ of demineralized water (electrical conductivity $3 \mu \mathrm{S} / \mathrm{cm}$ ) in a centrifuge tube. The immersed nanocomposite samples were maintained at ambient temperature for up to 3 months. In the study of organoclays, $0.2 \mathrm{~g}$ of organoclay were suspended in $25 \mathrm{~mL}$ of demineralized water and stirred for specified periods to obtain the release kinetics. After stirring, the organoclay was filtered out using cellulose filters with nominal pore size of $0.2 \mu \mathrm{m}$. A new portion of organoclay was used for each separate kinetic point. The electrical conductivity of the water in the tube containing nanocomposite samples and filtrates was measured using a CDM210 Conductivity Meter (Radiometer Analytical, France) equipped with CDC 745 conductivity cells.

Evaluation of antimicrobial activity

Gram-negative E. coli $\mathrm{BE}$ and gram-positive S. aureus CCM 209 bacteria strains were received from the Ukrainian Collection of Microorganisms. The bacteria were grown and maintained on Nutrient Agar No1 (Fluka). Microbial suspensions were prepared in sterilized physiological solution to reach a concentration of bacterial cells of $10^{7} \mathrm{CFU} \mathrm{mL} \mathrm{m}^{-1}$.

The MIC values of the organoclays were determined in $50 \mathrm{~mL}$ of organoclay suspension in sterile physiological 
solution seeded with $1 \mathrm{~mL}$ of bacterial suspension $\left(\sim 2 \times 10^{5} \mathrm{CFU} \mathrm{mL}{ }^{-1}\right)$. The concentrations of organoclays ranged from 0.1 to $1.0 \mathrm{mg} \mathrm{mL}^{-1}$. After $3 \mathrm{~h}$ of shaking the suspension at $30{ }^{\circ} \mathrm{C}, 50-\mu \mathrm{L}$ aliquots were spread on nutrient agar in Petri dishes and incubated for $24 \mathrm{~h}$ at $30{ }^{\circ} \mathrm{C}$. Bacterial count after contact with unmodified montmorillonite was used as a control. The MIC test was repeated at least three times for each organoclay.

To study the antimicrobial activity of the nanocomposites, $400 \mu \mathrm{L}$ of the bacterial suspension were located in the centre of a square piece of the material. The plastic piece was covered with a similar piece and the sandwich assembly was gently compressed to distribute bacterial suspension evenly across the plastic surfaces. The assembly was incubated for $24 \mathrm{~h}$ at $30^{\circ} \mathrm{C}$. After incubation, the two pieces were separated and placed such that nutrient agar faced onto the seeded side. After $1 \mathrm{~h}$, the plastic pieces were removed, leaving bacterial cells on the nutrient agar. The plates were incubated for $24 \mathrm{~h}$ at $30{ }^{\circ} \mathrm{C}$. Pieces of pristine Nylon 6 were used for control. The plates were examined for bacterial growth and compared with the plates of control samples to classify the antimicrobial activity in four categories: non-biocidal $(++++$ and +++ ), low active $(++)$, highly active $(+)$, and strongly biocidal (-). "+" is referred to viable cells and "-" referred to the absence of viable cells.

\section{Results and discussion}

Antimicrobial activity of organoclays

Depending on the molecular structure of the quaternary salts, the tested organoclays can be divided into two groups, i.e., organoclays with quaternary ammonium salts possessing a single long tail of hydrogenated tallow (Cloisite 10A, Cloisite 30B) and two long tails of hydrogenated tallow (Cloisite 15A, Cloisite 20B, Cloisite 93A), respectively. Initially, the antimicrobial activity of a series of commercially available organoclays modified with quaternary alkylammonium salts have been screened against gram-positive E. coli. All the investigated organoclays showed antimicrobial activity with Cloisite $10 \mathrm{~A}$ and Cloisite 30B being the most potent materials. The minimal inhibitory concentration (MIC) of these two organoclays was $0.5 \mathrm{mg} \mathrm{mL}^{-1}$. The MIC of Cloisite $15 \mathrm{~A}$ was higher, $1.0 \mathrm{mg} \mathrm{mL}^{-1}$. The least potential organoclays Cloisite 20A and Cloisite 93A cause complete inhibition of bacterial growth at concentrations notably higher than $1.0 \mathrm{mg} \mathrm{mL}^{-1}$.

Such a behavior is likely associated with the biocidal potentials of the ammonium salts. Cationic surfactants containing one long tail are more efficient than those with two long chains [17]. Moreover benzyl-containing surfactants (as in Cloisite 10A) are more active than those quaternary ammonium salts containing only aliphatic tails. Therefore, generally, the observed antimicrobial efficiencies of organoclays are consistent with the biocidal activity of the cationic surfactants used for clay modification. However, since organoclays contain different amounts of biocidal modifiers, direct correlation of the antimicrobial activity of organoclays and corresponding surfactants is inconclusive. For example, Cloisite 15A and Cloisite 20A are two grades of clay modified with the same cationic surfactant, with Cloisite 15A being more active, most likely as a result of a higher concentration of biocide.

Since biocides are exchangeable cations in an organoclay structure, they can migrate from the clay and thereby affect bacteria as soluble antimicrobial agents. The electrical conductivity of water-containing organoclay suspensions was monitored to estimate the release of the ammonium salts by surfactant-modified clays. As can be seen from Fig. 1, the rate of electrolyte migration and equilibrium values of the electric conductivity decreases in the following order: Cloisite $10 \mathrm{~A}>$ Cloisite $30 \mathrm{~B} \approx$ Cloisite $93 \mathrm{~A}>$ Cloisite 20A > Cloisite 15A. Interestingly, organoclay Cloisite 15A releases less biocide than Cloisite 20A despite having higher surfactant loading. Nevertheless Cloisite $15 \mathrm{~A}$ is more potent against bacteria. This suggests that the antimicrobial activity of an organoclay is not solely due to surfactants migrating from the clay surface into the aqueous phase.

Zone inhibition tests (results are not presented) demonstrated the formation of only small (if any) clear zones at the edge of the organoclays, supporting the contention that the antimicrobial activity of the organoclays is only partially due to migrating biocides. It worth noting that Dizman et al. [12] also indicated small inhibition zones for

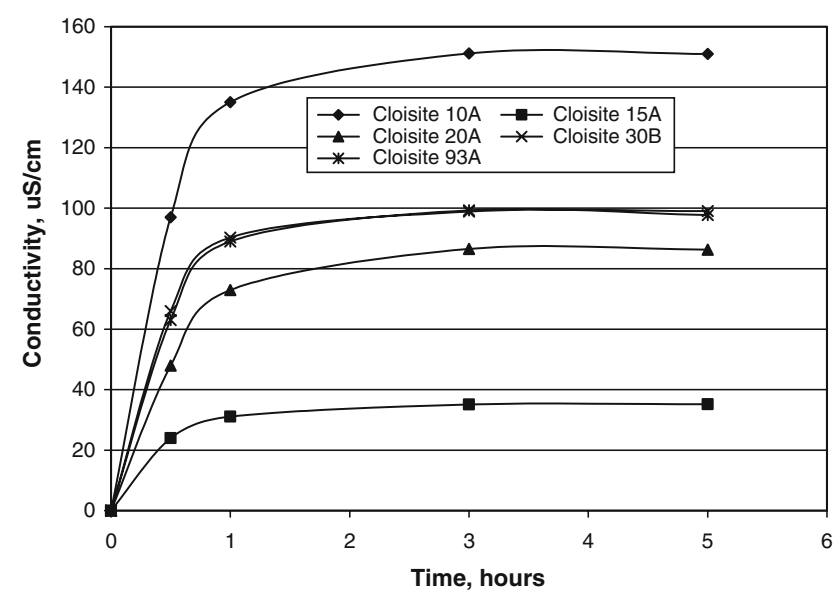

Fig. 1 Variation in electrical conductivity in the aqueous media after contacting with organoclays showing the release of cationic surfactants from the organoclays 
fluoromicas modified with quaternary ammonium substances. To further elucidate, the role of migrating biocide in the antimicrobial activity of organoclays, bacterial growth was studied in physiological solutions used for the elution of species migrating from the clay. In this experiment, the most active organoclays, Cloisite 10A and Cloisite 30B, were suspended in physiological solutions at a concentration of $0.5 \mathrm{mg} \mathrm{mL}^{-1}$ corresponding to their MIC value. After 2-hour stirring, the organoclays were filtered out and the filtrate was inoculated with E. coli $\left(10^{5} \mathrm{CFU} \mathrm{mL}{ }^{-1}\right)$ and incubated for $20 \mathrm{~h}$. The results obtained from bacterial count showed that the reduction of viable cells attained in the filtrate was $15 \%$, while practically complete inhibition of bacteria growth $(>95 \%)$ was observed in the clay suspension in the similar experiment.

These observations indicate that biocide migration is only partially responsible for the antimicrobial activity of organoclays. An organoclay with immobilized cationic surfactants can itself act as a solid biocide killing bacteria by contact. Previously, other research groups $[13,18]$ also postulated the surface contact mechanism for solid polymer materials containing cationic surfactants, which were loaded by ion exchange. Similar to our observation, in these studies, although the concentrations of surfactant migrated from such surfaces were well below the MIC of the biocidal surfactant, the solid materials were effective in the inhibition of bacterial growth.

Therefore, it appears that at least two mechanisms are responsible for the antimicrobial activity of the organoclays, i.e., activity of surfactants released from the clay and the action of the solid surface. Although the details of the latter mechanism have not yet been clarified, it may be reasonable to speculate that intimate contacts between a bacterial cell and antimicrobial surface may be crucial to affect the cell. These interactions are dependent on the surface properties of the cell and organoclay and, consequently, on supramolecular organization of the surfactants on the surface of the clay layers.

Depending on the surfactant content in an organoclay, long carbon chains of surfactant can be arranged between the clay sheets as mono- or bilayers parallel to the clay surface or as pseudotrimolecular layers or paraffin complexes. The surface properties and hydrophilic/hydrophobic balance of organoclays are determined by the supramolecular structure of the surfactants. Most hydrophobic organoclays are formed when the surfactant content was $110-130 \%$ with respect to cation exchange capacity (CEC) of the clay [19]. The surfactant content in Cloisite 15A lies in this range and therefore surfactant migration from Closite $15 \mathrm{~A}$ is slower than that from more hydrophilic Cloisite 20A. Somehow supramolecular organization in Cloisite 15A is more efficient in rendering the clay surface antimicrobial than in Cloisite 20A.
Antimicrobial activity of polymer nanocomposites

Following on from these observations of antimicrobial activity in the commercially available organoclays studied herein, a series of clay/nylon 6 nanocomposites have been prepared with the use of these organoclays to investigate the feasibility of rendering thermoplastics biocidal applying established polymer/clay nanotechnology.

It is widely recognized that the molecular structure and content of surfactants in clay are crucial in clay exfoliation in a polymer matrix. XRD analysis of the nanocomposites produced by melt extrusion showed that in all the nylon 6 nanocomposites the basal spacing between adjacent clay layers increased with respect to the corresponding original organoclay (Table 1). The structures formed are essentially intercalated. The increase in $d$-spacing is greater for the composites produced from the organoclays containing surfactants with two long tails. However for the organoclays containing the same type of surfactant but different content, Cloisite 15A and 20A, the clay with higher surfactant content (Cloisite 15A) resulted in a smaller increase in $d$-spacing compared with Cloisite 20A leveling the final values of $d$-spacing in the two nanocomposites, approximately $35 \mathrm{~A}$.

Nylon-6 and montmorillonite have relatively good affinity and polyamide/clay interactions are considered to be preferential compared to interactions between the polymer and hydrophobic surfactant tails [5]. Thus, overloading organoclay with surfactant sterically blocks the silicate surface and thereby diminishes polyamide/clay contacts. As a result, a smaller amount of polymer intercalates into the interlayer spacing of Cloisite 15A than Cloisite 20A.

Since combining a polyamide and an organoclay to form a nanocomposite is not accompanied with covalent binding of the surfactants, these hybrid materials are also expected to release surfactants. This hypothesis was examined by measuring the electrical conductivity of water containing a fixed sample size of immersed nanocomposite. As shown in the Fig. 2, all the composite materials exhibit leaching. Similarly migration of cationic surfactant from PU

Table 1 Basal spacing of organoclays and corresponding Nylon 6 nanocomposites

\begin{tabular}{lll}
\hline Organoclay & $\begin{array}{l}d_{001} \text { of } \\
\text { organoclays }(\AA)\end{array}$ & $\begin{array}{l}d \text {-spacing gain in } \\
\text { nanocomposite }(\AA)\end{array}$ \\
\hline Cloisite Na+ & 11.7 & - \\
Cloisite 10A & 18.4 & 3.6 \\
Cloisite 30B & 17.9 & 5.2 \\
Cloisite 15A & 30.4 & 4.8 \\
Cloisite 20A & 21.5 & 13.0 \\
Cloisite 93A & 23.5 & 6.1 \\
\hline
\end{tabular}




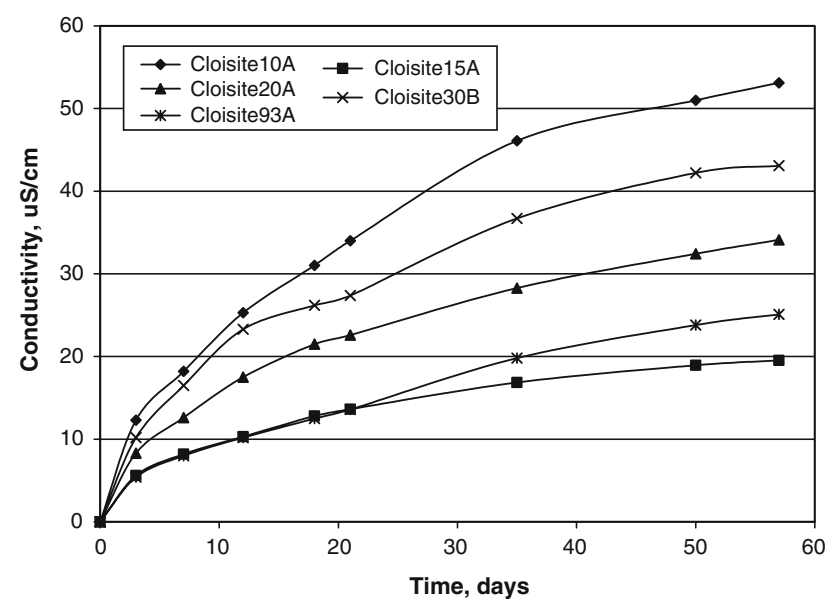

Fig. 2 Variation of electrical conductivity in aqueous media after contacting with nanocomposites showing the release of cationic surfactants from the nanocomposites

nanocomposites has been recently demonstrated using liquid chromatography-mass spectroscopy and cytotoxicity tests of leachates [20].

Naturally, migration of surfactants from the polymer composite is drastically slowed compared with the corresponding release rate of the surfactants from the respective organoclays alone. Similar to the organoclay results, leaching of the most hydrophilic surfactants (used for the preparation of Cloisite 10A and Closite 30B) was quicker for the corresponding polymer/clay composites. At the same time, surfactant release from the composite with Cloisite $93 \mathrm{~A}$ is slower than that from the composite produced using Closite 20A, despite the fact that an opposite trend was observed with the counterpart organoclays. Such leaching behavior may be associated with the bonding strength of the surfactants on the surface of clay and the nano-structure of the composites.

The bactericidal activity of the polymer/clay nanocomposites produced was tested against gram-positive $S$. aureus and gram-negative $E$. coli by the determination of the viability of the cells spread over the flat surface of composite plates. A semi-quantitative method has been applied for the characterization of antimicrobial activity of solid polymer surfaces. The method classifies the antimicrobial activity of the materials into four categories: non-biocidal $(++++$ and +++$)$, low active $(++)$, highly active $(+)$, and strongly biocidal (-) with " + " referring to the extent of viable cells and "-" referring to the absence of viable cells. As can be seen from Table 2, for composites containing $5 \%$ of organoclays, the material with Cloisite 30B was strongly biocidal against both the grampositive and gram-negative bacteria tested. Other composites showed high activity against $E$. coli and moderate activity against S. aureus. However the nanocomposite with Cloisite 10A was highly active against S. aureus. Antimicrobial activity of the nanocomposites increases with an increase in the organoclay loading. For example, an increase in the content of organoclay Cloisite 15A in the composites from $5 \%$ to $10 \%$, led to a nanocomposite which was classified as strongly biocidal against $E$. coli (Table 2).

Taking into account the slow migration rate of the biocides from the polymer/clay nanocomposites, it is reasonable to assume that the antimicrobial action of the composites is dominated by the solid surface mode rather than the migration mode. There are some indications that the antimicrobial activity of polymer/clay nanocomposites depends on supramolecular organization of the surfactants and the nano-structure of the composites. For example, the composite produced from Cloisite 30B was the most active material in spite of it having the lowest surfactant content in the organoclay, i.e., $90 \%$ of surfactant with respect to CEC. Only Cloisite 93A has similar content of surfactant. Although Cloisite 10A is as active as Cloisite 30B, and releases surfactant faster, its nanocomposite is less efficient than the composite containing Cloisite 30B. These observations suggest that the antimicrobial activity of clay/ polymer nanocomposites is a function of not only the biocidal activity of the surfactants, but also the nanostructure of the composites. Synergy effects may also be involved. Our current research is focused on gaining more insights into these relations.

It is worth noting that test bacteria studied herein have different abilities to grow on the surface of pristine nylon6. Gram-positive S. aureus is more prolific than E. coli and spread evenly across the surface. This makes it difficult to discriminate the individual colonies of $S$. aureus on the surface of pristine nylon-6. Since the cell viability was estimated by reference to pristine nylon- 6 , differences in

Table 2 Antimicrobial activity of polyamide/clay nanocomposites containing 5 wt. \% of different Cloisite organoclays

\begin{tabular}{|c|c|c|c|c|c|c|}
\hline Bacteria & Nylon 6 (control) & Cloisite 10A & Cloisite 30B & Cloisite $15 \mathrm{~A}^{\mathrm{a}}$ & Cloisite 20A & Cloisite 93A \\
\hline E. coli & +++ & + & - & $\begin{array}{l}+++(1 \%) \\
++(2 \%) \\
+(5 \%) \\
-(10 \%)\end{array}$ & + & + \\
\hline S. aureus & ++++ & + & - & ++ & ++ & ++ \\
\hline
\end{tabular}

${ }^{a}$ Content of Cloisite $15 \mathrm{~A}$ in nanocomposites is shown in parentheses 
cell growth on control (bare polyamide) samples can lead to a misinterpretation of the susceptibility of different cells to the antimicrobial action of the polymer/clay nanocomposites. Therefore the reported higher grades of biocidal activity for nanocomposites against E. coli (Table 2) do not necessarily mean that they are more active against gram-negative bacteria. From this point of view, further investigations are required to clarify the antimicrobial efficiency of the nanocomposites against gram-positive and gram-negative bacteria.

\section{Conclusions}

This study demonstrates a significantly overlooked function of organoclays modified with cationic surfactants for nanocomposite application, i.e., the ability of organoclays to render polymer nanocomposites biocidal. This finding is very significant and opens the way for the highly appraised polymer/clay nanotechnology to enable robust processing of polymers into antimicrobial materials, with the substantial additional benefits of improved engineering properties. This approach provides an alternative to surface modification or coating technologies in the production of self-sterilizing surfaces. However, the present study together with the reports of another research group [20, 21] show that the biocidal modifiers migrate from the clay and nanocomposites. Therefore, the existing polymer/clay technology, based on commercially available organoclays, can be applied only in fields where surfactant migration is acceptable, for example, textiles, furniture, electronics, etc. Prevention of biocide migration will widen the applicability of antimicrobial clay/polymer nanocomposites. This problem is addressed in our current research on the development of non-leaching biocidal organoclays.

\section{References}

1. Gao F (2004) Mater Today 7:50. doi:10.1016/S13697021(04)00509-7

2. Ray SS, Okamoto M (2003) Prog Polym Sci 28:1539. doi: 10.1016/j.progpolymsci.2003.08.002

3. Zeng QH, Yu AB, Lu GQ, Paul DR (2005) J Nanosci Nanotechnol 5:1574. doi:10.1166/jnn.2005.411

4. Usuki A, Hasegawa N, Kato M (2005) Adv Polym Sci 179:135

5. Fornes TD, Hunter DL, Paul DR (2004) Macromolecules 37:1793. doi:10.1021/ma0305481

6. Yang I-K, Tsai P-H (2006) Polymer 47:5131. doi:10.1016/ j.polymer.2006.04.065

7. Hugo WB, Russell AD (1999) In: Russell AD, Hugo WB, Ayliff GAJ (eds) Principles and practice of disinfection preservation and sterilisation. Blackwell Science, Oxford

8. Ohashi F, Oya A, Duclaux L, Beguin F (1998) Appl Clay Sci 12:435. doi:10.1016/S0169-1317(98)00008-8

9. Patakfalvi R, Dékány I (2004) Appl Clay Sci 25:149. doi: 10.1016/j.clay.2003.08.007

10. Li B, Yu S, Hwang JY, Shi S (2002) J Min Mater Charact Eng 1:61

11. US Patent $4,929,644$ (1990)

12. Dizman B, Badger JC, Elasri MO, Mathias LJ (2007) Appl Clay Sci 38:57. doi:10.1016/j.clay.2007.01.002

13. Herrera P, Burghardt RC, Philips TD (2000) Vet Microbiol 74:259. doi:10.1016/S0378-1135(00)00157-7

14. He H, Yang D, Yuan P, Shen W, Frost RL (2006) J Colloid Interface Sci 297:235. doi:10.1016/j.jcis.2005.10.031

15. Wang X, Du Y, Yang J, Wang X, Shi X, Hu Y (2006) Polymer (Guildf) 47:6738. doi:10.1016/j.polymer.2006.07.026

16. Wang X, Du Y, Yang J, Tang Y, Luo J (2008) J Biomed Mater Res A 84:384. doi:10.1002/jbm.a.31326

17. Steichen DS (2002) In: Holmberg K (ed) Handbook of applied surface and colloid chemistry, vol 1 . Willey, Chichester

18. Tiller JC, Sprich C, Hartmann L (2005) J Control Release 103:355. doi:10.1016/j.jconrel.2004.12.002

19. Mandalia T, Bergaya F (2006) J Phys Chem Solids 67:836. doi: 10.1016/j.jpcs.2005.12.007

20. Styan KE, Martin DJ, Poole-Warren LA (2008) J Biomed Mater Res A (Epub ahead of print)

21. Styan K, Abrahamian M, Hume E, Poole-Warren LA (2007) Key Eng Mater 342-343:757 